\title{
DESIGN OF A FLEXIBLE DEFOLIATOR FOR MAIZE STRAW
}

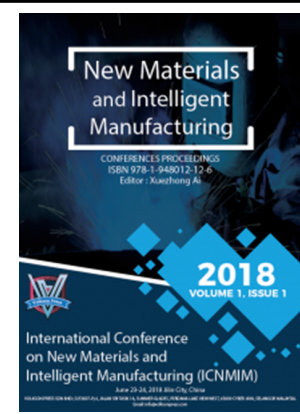

\author{
Hou Zhesheng*, Bao Penglai and Wang Meng \\ College of Mechanical \& Electrical Engineering, Jilin Institute of Chemical Technology, Chengde Street, Jilin City, JilinChina \\ *Corresponding Author E-mail: 13844675398@126.com
}

This is an open access article distributed under the Creative Commons Attribution License, which permits unrestricted use, distribution, and reproduction in any medium, provided the original work is properly cited.

\section{ARTICLE DETAILS}

Article History:

Received 26 June 2018

Accepted 2 July 2018

Available online 1 August 2018

\begin{abstract}
This article contains a flexible defoliator for maize straw, the device including material platform, feeding mechanism, guide mechanism, the first to defoliator institutions, the second to defoliator institutions, output structure and straw crushed leaves collection agencies. The feeding mechanism consists of two rollers at both ends, which are connected by spring or elastic plate and box body. The first defoliator is made of rubber with a spiral gear wheel with a steel pointed structure, which is connected with the box body by spring or elastic plate. The second defoliator is the roller for internal screw mounting steel wire; The organization is located on the same line; Both the guide mechanism and the defoliator are provided with the material outlet and the straw scrap recovery device. In this article, the design structure of the device is compact, which solves the problem that the straw leaves are not sufficient, and the flexible leaves of straw are truly realized.
\end{abstract}

\section{KEYWORDS}

Corn harvester; Defoliator device.

\section{INTRODUCTION}

Based on a study, maize sowing and reaping the comprehensive level of mechanization in our country is $42.8 \%$, the mechanical plough level is $60 \%$, seeding rate was $59 \%$, the yield is $7.2 \%$, for a long time, the corn harvester is the bottleneck of corn production mechanization [1]. The processing of straw is an unavoidable problem in the process of maize harvest at home and abroad. At present, some harvesters at home and abroad have harvested or crushed the corn cob $[2,3]$. The first corn harvester originated in the United States. In 1939, the United States successfully developed the first self-propelled corn combined harvester. According to research, some countries with relatively developed economies also began to study the production and use of corn combine harvesters [4]. Research showed corn harvester technology in China in the 1970s, for the introduction of foreign advanced type and generic, after the stage of development, our country has had the independent ability to design and develop new products $[5,6]$.

Device described in this paper to solve the technical problems of the above, the main solution to maize straw it device problem of transmission congestion, stack maize straw in the process of two leaf peeling problem of poor effect. In addition, a more stable, high efficiency, high separation rate, and corn straw with less damage to maize straw are provided.

\section{INTRODUCTION TO THE STRUCTURE OF THE FLEXIBLE DEFOLIATOR OF CORN STALK}

\subsection{Feeding Mechanism}

Figure 1 shows the main view of the feeding mechanism of the corn straw flexible defoliator. It consists of two sets of roller wheels, which are located in the front of the feeding platform and before the guiding mechanism. Two groups of conveying mechanism adopt constant reverse rotation, on the circumference of a non-uniform random distribution of the circular protuberance of the roller, two groups of the roller on the bump height is unfavorable and exorbitant, phase error, and the first set of feed roller at both ends with a spring or elastic plate will be the first group of roller shaft connected to the box body, a second set of feed roller wheel directly connected to the enclosure. As shown in figure 2 on the left side of the feed roller can realize the flexible feeding, stacking bundles or flattening of feed corn stover, and on the right side of the roller after flattening straw into to the back of the steering mechanism. The bump on the roller increases the friction between the roller and the corn stalk, which can effectively prevent the slipping of the corn stalk in the transmission process, so as to facilitate the next transmission of the corn stalk.

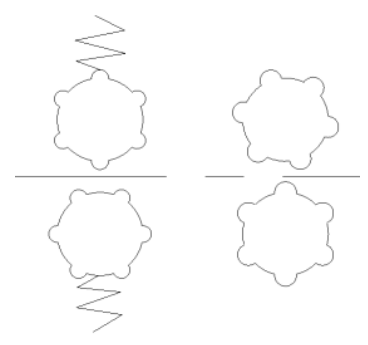

Figure 1: Feeding Mechanism

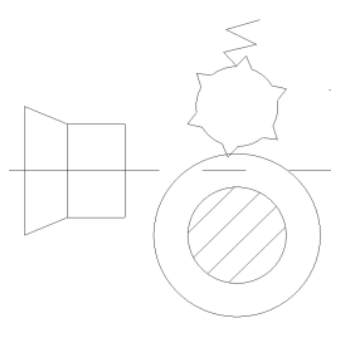

Figure 2: Guide Mechanism

\subsection{Guide Mechanism}

Figure 2 is the main view of the guiding mechanism of the flexible defoliator of corn straw, which is located in the feeding device. The guiding mechanism consists of two parts, the first guiding mechanism on the left and the second guiding mechanism on the right. Among them, the first steering mechanism for the first half is conical, cylindrical part shown after the connection of the body, its purpose is to send the by conveying mechanism of maize straw for individual or double bead, and then enter the second steering mechanism. Second steering mechanism is composed 
of the puller roller wheel and sheave, the puller roller for surface with pyramidal tip shape bump of the roller, the uneven random arrangement, its purpose is to increase the friction roller with straw, to prevent the occurrence of slippage phenomenon, straw and puller roller ends with a spring or elastic plate connected to the box body, steering mechanism of the surface of the sheave is smooth surface, directly connected to the enclosure. The second feeding mechanism sends the single plant or double beaded corn stalk into the first defoliator in the direction of the groove wheel, which ensures that the corn stalk will not deviate from the predetermined orbit.

\subsection{The First to Defoliator Institutions}

Figure 3 shows the main view of the first leaf mechanism of maize straw flexible defoliator. First to leaf institutions is based on the principle of bionics, the structure of the reference bears the tongue, it is made from rubber, helical gear of the roller, the addendum with steel tip shape prominent structure, highlight the height is unfavorable and exorbitant, and evenly distributed on the surface, as described in the roller with spring or elastic plate connect roller shaft and housing, and two roller adopt constant speed reverse, and corn stover movement in the opposite direction of rotation. Is the purpose of the first to leaf organization will by the steering mechanism into the preliminary remove stalks, corn stalks can be adaptive to different degree of thickness of straw, and will remove the maize straw crushed leaves along a fixed direction, facilitate the straw crushed leaves collection.

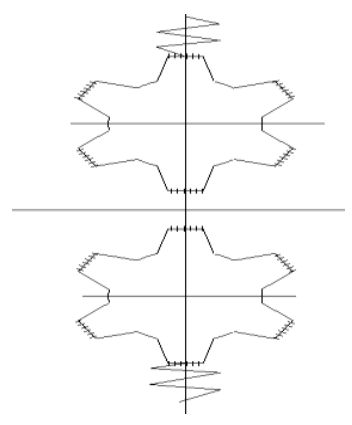

Figure 3: The First to Defoliator Institutions

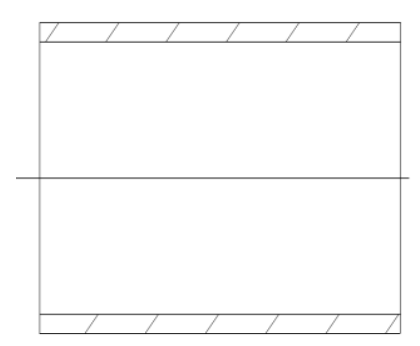

Figure 4: The Second to Defoliator Institutions

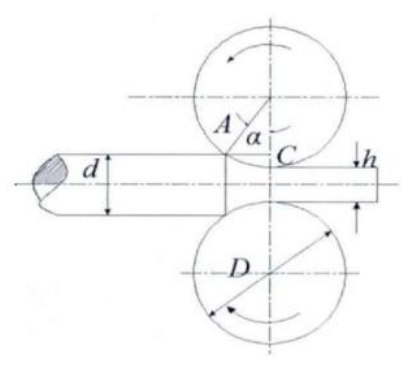

Figure 5: The Relationship Between the Initial Grab Angle and the Feed Roller Parameters

\subsection{The Second to Defoliator Institutions}

Figure 4. shows the main view of the second leaf mechanism of the flexible defoliator of maize straw. Second to leaf institutions is based on the bionics principle, the principle of reference hand twist things, internal cylinder with steel structure arrangement, and steel wire arrangement is in the shape of spiral uniform distribution on the inner surface of the drum, the distance of the spiral should not be too small, should be moderate, the axis of the drum line with installation of other institutions in the same line, and do optimal speed rotary motion. The purpose is to make the remaining straw fragments to be twisted by a diagonal, so that the smaller force can be removed, and the power consumption can be reduced. The shell of the drum is a discontinuous strip structure with the purpose of easy removal of the corn stalk leaves falling, which is convenient for the collection of straw shredded leaves.

\subsection{Straw Crushed Leaves Collection Agencies}

Figure 5 shows the main view of the straw scrap recycling mechanism of corn stalk flexible defoliator. The device consists of a transmission turbine, a feeding port, a motor and a straw broken leaf collecting box. Drive turbine horizontal position, driven by motor; The material port is located at the bottom of the feeding mechanism, the guiding mechanism, the first defoliator and the second defoliator. The recovery unit is used to recycle the discarded corn stalk to make a comprehensive utilization of the stalk.

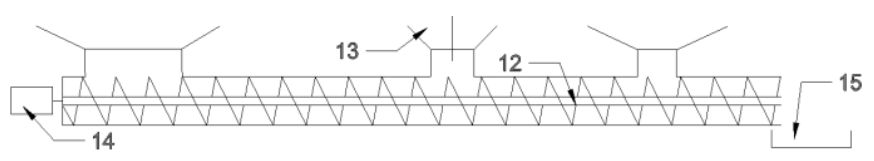

Figure 6: Straw Crushed Leaves Collection Agencies

\section{DETERMINATION AND CALCULATION OF RELATED PARAMETERS}

In the experiment, the maize was selected with the Jidan 209, the average height of the maize variety was $1955 \sim 2005 \mathrm{~mm}$, the average diameter of the stalk root was $29-33 \mathrm{~mm}$, and the average diameter of the ear was 24 $\sim 28 \mathrm{~mm}$ [7]. Based on a study, the maize straw was selected to cut off the stalk and root of straw, without the separation of the stems and leaves, and in the indoor storage for 2 months, natural air drying, no mildew, and the average moisture content [8].

\subsection{The main parameters of feeding roller are determined}

The diameter $\mathrm{D}$ and working clearance $\mathrm{h}$ of the picking roller: the picking roller can grasp the stalk of maize, and the initial grasping of the Angle of the extraction process should not be too large [9]. It is well known by figure 6 .

$$
\cos \alpha=\frac{\mathrm{OC}}{\mathrm{OA}}=\frac{\mathrm{D}+\mathrm{h}-\mathrm{d}}{\mathrm{D}}
$$

Increasing the diameter $\mathrm{D}$ of the feed roller and $\mathrm{h}$ or grasping the minimum stem can reduce the initial grasping Angle of the picking roller, which is beneficial to the grasping of the stalk in the working process.

By formula (1):

$$
\mathrm{D}=\frac{\mathrm{d}-\mathrm{h}}{1-\cos \alpha}
$$

By $\mathrm{f}_{0} \geq \tan \alpha$ and $\cos \alpha=\frac{1}{\sqrt{1+\tan ^{2} \alpha}}$

$$
\text { So } \mathrm{D} \geq \frac{\mathrm{d}-\mathrm{h}}{1-\frac{1}{\sqrt{1+\mathrm{f}_{0}^{2}}}}
$$

In the formula, the friction coefficient between the feeding roller and the stem, $\mathrm{f}_{0}=0.7 \sim 1.1, \mathrm{f}_{0}=1$. The clearance of general feeding roller is $\mathrm{h}=$ (0.1 1.4)d, h=10mm [10].

Calculated:D $\geq 78.53 \mathrm{~mm}, \quad \mathrm{D}=100 \mathrm{~mm}$.

\subsection{Calculation of Leaf Removal Rate of Corn Stalk Leaves}

Defoliation rate is the only evaluation index of separation effect. The bigger the leaf, the better. Stem leaf separation experiment was carried out before without separation, the quality of the straw $M_{1}(\mathrm{~kg})$, as the rest of the straw quality after testing machine separation $M_{2}(\mathrm{~kg})$, manual peel off residue on the straw leaf stem said again after take the quality as $M_{3}$ (kg).You have to go to leaf rate $\mathrm{y}$. The calculation formula is [11]

$$
y=\frac{M_{1}-M_{2}}{M_{1}-M_{3}} \times 100 \%
$$

It was found that the optimal solution for the separation of stalks and leaves of maize straw was: the rotation speed of the leaf roller was 
$200 \mathrm{r} / \mathrm{min}$, the clearance of the roller was $8 \mathrm{~mm}$, and the roller speed ratio was 1.6. Under this condition, the leaf rate of the test machine was $92.9 \%$. However, in this condition, although the leaf rate was the highest, the damage rate of maize straw was higher than that of other groups.

The rate of defoliation and the rotational speed of the defoliation axis were in a convex parabolic relationship, while the failure rate of the stem was linear with that of the defoliation axis. The higher the rotation speed, the higher the damage rate. According to a study, when the rotational speed of the defoliation axis is $1100 \sim 1200 \mathrm{r} / \mathrm{min}$, the damage rate of the stem is between2 3\% [12]. Therefore, the optimal separation condition is: rotational speed is $1120 \mathrm{r} / \mathrm{min}$.

\section{THE WORKING PRINCIPLE OF THE FLEXIBLE DEFOLIATOR OF MAIZE STRAW}

The working process of the flexible defoliator for maize straw is as follows: Artificial will stay after the removal of corn cob processing of corn stover (1)、(2) on the loading area of the inlet, the motor drives the conveying mechanism (3), (4) the rotation, corn stover (1) by the conveying mechanism (3) into the roll wheel, roll wheel (3) that are stacked to corn stover (1), and sent it to the conveying mechanism of the roll wheel (4), the corn straw (1) further sorting, to guide device (5), (1) the corn stalk, and sent to the steering mechanism (6),By the guide roller (6-1) on the cone tip structure will be corn stover (1) into (7) to the first leaf group, due to its flexible, can adjust (1) the thickness of corn stalk, preliminary to leaf, corn straw (1) to (7) by the first leaves the puller roller (8) after pulling away preliminary to leaf of maize straw, and sent to the second (9) leaf group, because the second leaf agency (9) has certain rigidity and flexibility of steel structure, for preliminary to a thorough to leaves, leaf of maize straw especially for a hard structure of the corn straw stalk section of straw skin effect is remarkable. Because of the spiral shape of the steel wire structure in the drum, it has a spiral shape, which makes the corn stalk broken leaves off the second defoliation mechanism (9).The maize straw after the leaves is pulled out by the puller roller (10), and the leaves of the corn stalk (1) are completed through the outlet (11).At the same time, the corn straw (1) through feeding device (3) (4) the loss of corn straw crushed leaves and the first leaf institutions (7) produced by corn stalk broken leaf and second leaf agency (9) the corn straw crushed leaves which produced through the mouth of the corresponding mechanism set below into another (14) driven by a motor device (12) of corn stover, was eventually sent to the maize straw broken boxes (15).

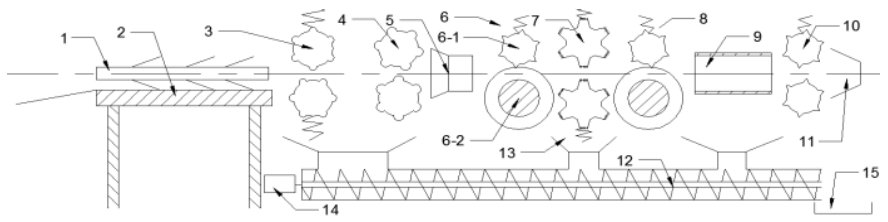

Figure 7: Overall Main View of Corn Stalk Flexible Defoliator

\section{CONCLUSION}

In this paper, the flexible defoliating device of maize straw isn't used in the transmission of straw. The guiding mechanism of the device in front of the defoliator is very good to ensure the orientation of straw in the process of defoliation. This device adopts the double leaf institutions, straw to leaf

\section{ACKNOWLEDGMENTS}

Fund Project: Significant Scientific and Technical Project in Jilin (20170201003GX) effect is more obvious, especially the second to institutions, not only can deal with small maize straw to skin problems, can also process because the corn straw stalk section of straw skin good and should not remove the problem, make the maize straw to leaf is more efficient; The device of maize straw crushed leaves recovery unit, will be exploited down corn stalk crushed leaves recycle, namely to leaf institutions provide relatively good working space, and for the later use of corn straw crushed leaves do preparation. In this paper, the structure is more compact, the work is more reliable, the skin efficiency is high, and the flexible peeling is realized.

\section{REFERENCES}

[1] Ming, Z. 2015. Self-propelled corn harvester virtual design. Applied Mechanics and Materials, 3759 (727), 505-508.

[2] Zou, L., Zhuo, J.Q., Yang, R.Q. 2008. Development prospect of corn harvester in China. Agricultural mechanization research, (4), 205-208.

[3] Liu, Z.J. 2017. The promotion of crop stalks and straw harvesting harvesters to improve the straw mulching in the main producing areas of corn[J]. Agricultural development and equipment, 189 (9), 52.

[4] Ye, T., Chang, J.G., Lin, J.T. 2016. Current situation and development trend of corn combine harvester at home and abroad. Agricultural machinery use and maintenance, 238 (6), 19-21.

[5] Wang, Y.J. 2009. A review of corn harvest mechanization. Science and technology information, (5), 473.

[6] Dong, Y.F. 2008. Research report on China's corn harvest mechanization development. Contemporary agricultural machinery, (9), $16-18$.

[7] Wang, G., Jia, H.L., Zhao, J.L. 2014. Design of stubble cutter for maize and stubble effect test. Journal of Agricultural Engineering, 30, 249 (23), 51-57.

[8] Liu, X.J., Yuan, Z.B. 2017. Design of Smart Car Control System Based on Camera Acta Electronica Malaysia, 1 (1), 12-14.

[9] Lan, Z.T. 2017. Design and study of harvesting machine cutting platform of straw recycling corn harvester. Shenyang Agricultural University.

[10] Li, P.F., Hua, J., Zhang, X.M. 2013. Design and research on the separation of pulp and leaf of maize straw. Anhui agricultural science, 41, (33), 13039-13041.

[11] Zhu, X.H., Yang, Z.P., Guo, K.Q. 2011. Design and experiment of maize straw defoliation device. Zhu Xinhua. China agricultural engineering society, 1969-1974.

[12] Gao, M.X. 2011. Experimental study on the separation mechanism of stalks and leaves of maize straw. Northwest agriculture and forestry university.

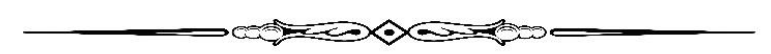

